\title{
Hybrid mixed type iteration scheme for asymptotically nonexpansive mappings and total asymptotically nonexpansive non-self mappings
}

\author{
G.S. SAluja
}

\begin{abstract}
In this paper, we proposed a new two-step iteration scheme of hybrid mixed type for two asymptotically nonexpansive self mappings and two total asymptotically nonexpansive non-self mappings and establish some strong convergence theorems for mentioned scheme and mappings in real Banach spaces. Our results extend and generalize several results from the current existing literature.
\end{abstract}

\section{Introduction AND PRELIMINARIES}

Let $K$ be a nonempty subset of a real Banach space $E$. Let $T: K \rightarrow K$ be a nonlinear mapping, then we denote the set of all fixed points of $T$ by $F(T)$. The set of common fixed points of four mappings $S_{1}, S_{2}, T_{1}$ and $T_{2}$ will be denoted by $F=F\left(S_{1}\right) \bigcap F\left(S_{2}\right) \bigcap F\left(T_{1}\right) \bigcap F\left(T_{2}\right)$.

Definition 1.1. A mapping $T: K \rightarrow K$ is said to be asymptotically nonexpansive [5] if there exists a positive sequence $\left\{k_{n}\right\}$ in $[1, \infty)$ with $\lim _{n \rightarrow \infty} k_{n}=$ 1 such that

$$
\left\|T^{n}(x)-T^{n}(y)\right\| \leq k_{n}\|x-y\|
$$

for all $x, y \in K$ and $n \in \mathbf{N}$.

The class of asymptotically nonexpansive mappings was introduced by Goebel and Kirk [5] as a generalization of the class of nonxpansive mappings. They proved that if $C$ is a nonempty closed convex subset of a real uniformly convex Banach space and $T$ is an asymptotically nonexpansive mapping on $C$, then $T$ has a fixed point.

2000 Mathematics Subject Classification. 47H09, 47H10, 47J25.

Key words and phrases. Asymptotically nonexpansive mapping, total asymptotically nonexpansive non-self mapping, hybrid mixed type iteration scheme, common fixed point, Banach space, strong convergence. 
Example 1.1. (See [5]) Let $D$ be the closed unit ball in the Hilbert space $H=\ell_{2}$ and $T: D \rightarrow D$ a mapping defined by

$$
T\left(x_{1}, x_{2}, x_{3}, \ldots\right)=\left(0, x_{1}^{2}, a_{2} x_{2}, a_{3} x_{3}, \ldots\right)
$$

where $\left\{a_{i}\right\}$ is a sequence of real numbers such that $0<a_{i}<1$ and $\prod_{i=2}^{\infty} a_{i}=\frac{1}{2}$.

Then

$$
\|T(x)-T(y)\| \leq 2\|x-y\| \text { for all } x, y \in D,
$$

that is, $T$ is Lipschitzian, but not nonexpansive.

Observe that

$$
\left\|T^{n}(x)-T^{n}(y)\right\| \leq 2\left(\prod_{i=2}^{n} a_{i}\right)\|x-y\| \text { for all } x, y \in D, n \geq 2 .
$$

Here $k_{n}=2 \prod_{i=2}^{n} a_{i} \rightarrow 1$ as $n \rightarrow \infty$. Therefore $T$ is an asymptotically nonexpansive mapping.

Definition 1.2. A mapping $T: K \rightarrow K$ is said to be total asymptotically nonexpansive [1] if

$$
\left\|T^{n}(x)-T^{n}(y)\right\| \leq\|x-y\|+\mu_{n} \psi(\|x-y\|)+\nu_{n},
$$

for all $x, y \in K$ and $n \in \mathbf{N}$, where $\left\{\mu_{n}\right\}$ and $\left\{\nu_{n}\right\}$ are nonnegative real sequences such that $\mu_{n} \rightarrow 0$ and $\nu_{n} \rightarrow 0$ as $n \rightarrow \infty$ and a strictly increasing continuous function $\psi:[0, \infty) \rightarrow[0, \infty)$ with $\psi(0)=0$.

From the above definition, we see that the class of total asymptotically nonexpansive mappings include the class of asymptotically nonexpansive mappings as a special case; see also [4] for more details.

Remark 1.1. From the above definition, it is clear that each asymptotically nonexpansive mapping is a total asymptotically nonexpansive mapping with $\nu_{n}=0, \mu_{n}=k_{n}-1$ for all $n \geq 1, \psi(t)=t, t \geq 0$.

Definition 1.3. A subset $K$ of a Banach space $E$ is said to be a retract of $E$ if there exists a continuous mapping $P: E \rightarrow K$ (called a retraction) such that $P(x)=x$ for all $x \in K$. If, in addition $P$ is nonexpansive, then $P$ is said to be a nonexpansive retract of $E$.

If $P: E \rightarrow K$ is a retraction, then $P^{2}=P$. A retract of a Hausdorff space must be a closed subset. Every closed convex subset of a uniformly convex Banach space is a retract.

Definition 1.4. Let $K$ be a nonempty closed and convex subset of a Banach space $E$. A non-self mapping $T: K \rightarrow E$ is said to be total asymptotically nonexpansive [14] if there exist sequences $\left\{\mu_{n}\right\}$ and $\left\{\nu_{n}\right\}$ in $[0, \infty)$ with 
$\mu_{n} \rightarrow 0$ and $\nu_{n} \rightarrow 0$ as $n \rightarrow \infty$ and a strictly increasing continuous function $\psi:[0, \infty) \rightarrow[0, \infty)$ with $\psi(0)=0$ such that

(3) $\left\|T(P T)^{n-1}(x)-T(P T)^{n-1}(y)\right\| \leq\|x-y\|+\mu_{n} \psi(\|x-y\|)+\nu_{n}$,

for all $x, y \in K$ and $n \in \mathbf{N}$.

Example 1.2. Let $E$ be the real line with the usual norm |.|, $C=[0, \infty)$ and $P$ be the identity mapping. Assume that $T_{1}(x)=x$ and $T_{2}(x)=\sin x$ for all $x \in C$. Let $\phi$ be the strictly increasing continuous function such that $\phi: \mathbb{R}^{+} \rightarrow \mathbb{R}^{+}$with $\phi(0)=0$. Let $\left\{\mu_{n}\right\}_{n \geq 1}$ and $\left\{\nu_{n}\right\}_{n \geq 1}$ be two nonnegative real sequences defined by $\mu_{n}=\frac{1}{n^{2}}$ and $\nu_{n}=\frac{1}{n^{3}}$ for all $n \geq 1$ with $\mu_{n} \rightarrow 0$ and $\nu_{n} \rightarrow 0$ as $n \rightarrow \infty$. Then $T_{1}$ and $T_{2}$ are total asymptotically nonexpansive mappings with common fixed point 0 , that is, $F=F\left(T_{1}\right) \cap F\left(T_{2}\right)=\{0\}$.

Definition 1.5. A mapping $T: K \rightarrow K$ is said to be completely continuous if $\left\{T x_{n}\right\}$ has a convergent subsequence in $K$ whenever $\left\{x_{n}\right\}$ is bounded in $K$.

Definition 1.6. A mapping $T: K \rightarrow K$ is said to be semi-compact if for any bounded sequence $\left\{x_{n}\right\}$ in $K$ such that $\left\|x_{n}-T x_{n}\right\| \rightarrow 0$ as $n \rightarrow \infty$, then there exists a subsequence $\left\{x_{n_{r}}\right\} \subset\left\{x_{n}\right\}$ such that $x_{n_{r}} \rightarrow x^{*} \in K$ strongly as $r \rightarrow \infty$.

In 2004, Chidume et al. [3] studied the following iteration scheme:

$$
\begin{aligned}
x_{1} & =x \in K, \\
x_{n+1} & =P\left(\alpha_{n} T(P T)^{n-1} x_{n}+\left(1-\alpha_{n}\right) x_{n}\right), n \geq 1,
\end{aligned}
$$

where $\left\{\alpha_{n}\right\}$ is a sequence in $(0,1)$, and $K$ is a nonempty closed convex subset of a real uniformly convex Banach space $E, P$ is a nonexpansive retraction of $E$ onto $K$, and proved some strong and weak convergence theorems for asymptotically nonexpansive non-self mappings in the intermediate sense in the framework of uniformly convex Banach spaces.

In 2006, Wang [12] generalized the iteration process (4) as follows:

$$
\begin{aligned}
x_{1} & =x \in K, \\
x_{n+1} & =P\left(\left(1-\alpha_{n}\right) x_{n}+\alpha_{n} T_{1}\left(P T_{1}\right)^{n-1} y_{n}\right), \\
y_{n} & =P\left(\left(1-\beta_{n}\right) x_{n}+\beta_{n} T_{2}\left(P T_{2}\right)^{n-1} x_{n}\right), n \geq 1,
\end{aligned}
$$

where $T_{1}, T_{2}: K \rightarrow E$ are two asymptotically nonexpansive non-self mappings and $\left\{\alpha_{n}\right\},\left\{\beta_{n}\right\}$ are real sequences in $[0,1)$, and proved some strong and weak convergence theorems for asymptotically nonexpansive non-self mappings.

In 2012, Guo et al. [6] generalized the iteration process (5) as follows:

$$
x_{1}=x \in K,
$$




$$
\begin{aligned}
x_{n+1} & =P\left(\left(1-\alpha_{n}\right) S_{1}^{n} x_{n}+\alpha_{n} T_{1}\left(P T_{1}\right)^{n-1} y_{n}\right), \\
y_{n} & =P\left(\left(1-\beta_{n}\right) S_{2}^{n} x_{n}+\beta_{n} T_{2}\left(P T_{2}\right)^{n-1} x_{n}\right), n \geq 1,
\end{aligned}
$$

where $S_{1}, S_{2}: K \rightarrow K$ are two asymptotically nonexpansive self mappings and $T_{1}, T_{2}: K \rightarrow E$ are two asymptotically nonexpansive non-self mappings and $\left\{\alpha_{n}\right\},\left\{\beta_{n}\right\}$ are real sequences in $[0,1)$, and proved some strong and weak convergence theorems for mixed type asymptotically nonexpansive mappings.

Now, we define the hybrid mixed type iteration scheme.

Let $E$ be a real Banach space, $K$ be a nonempty closed convex subset of $E$ and $P: E \rightarrow K$ be a nonexpansive retraction of $E$ onto $K$. Let $S_{1}, S_{2}: K \rightarrow$ $K$ be two asymptotically nonexpansive self mappings and $T_{1}, T_{2}: K \rightarrow E$ are two total asymptotically nonexpansive non-self mappings. Then the hybrid mixed type iteration scheme for the mentioned mappings is as follows:

$$
\begin{aligned}
x_{1} & =x \in K, \\
x_{n+1} & =P\left(\left(1-\alpha_{n}\right) S_{1}^{n} x_{n}+\alpha_{n} T_{1}\left(P T_{1}\right)^{n-1} y_{n}\right), \\
y_{n} & =P\left(\left(1-\beta_{n}\right) S_{2}^{n} x_{n}+\beta_{n} T_{2}\left(P T_{2}\right)^{n-1} x_{n}\right), n \geq 1,
\end{aligned}
$$

where $\left\{\alpha_{n}\right\}$ and $\left\{\beta_{n}\right\}$ are real sequences in $[0,1)$.

The purpose of this paper is to study newly proposed hybrid mixed type iteration scheme (7) and establish some strong convergence theorems in the setting of real Banach spaces.

Next, we need the following useful lemma to prove our main results.

Lemma 1.1. (See [11]) Let $\left\{\alpha_{n}\right\}_{n=1}^{\infty},\left\{\beta_{n}\right\}_{n=1}^{\infty}$ and $\left\{r_{n}\right\}_{n=1}^{\infty}$ be sequences of nonnegative numbers satisfying the inequality

$$
\alpha_{n+1} \leq\left(1+\beta_{n}\right) \alpha_{n}+r_{n}, \forall n \geq 1 .
$$

If $\sum_{n=1}^{\infty} \beta_{n}<\infty$ and $\sum_{n=1}^{\infty} r_{n}<\infty$, then

(i) $\lim _{n \rightarrow \infty} \alpha_{n}$ exists;

(ii) In particular, if $\left\{\alpha_{n}\right\}_{n=1}^{\infty}$ has a subsequence which converges strongly to zero, then $\lim _{n \rightarrow \infty} \alpha_{n}=0$.

\section{MAin Results}

In this section, we prove some strong convergence theorems of iteration scheme (7) for two asymptotically nonexpansive mappings and two total asymptotically nonexpansive non-self mappings in real Banach spaces. First, we shall need the following lemma. 
Lemma 2.1. Let $E$ be a real Banach space, $K$ be a nonempty closed convex subset of $E$. Let $S_{1}, S_{2}: K \rightarrow K$ be two asymptotically nonexpansive self mappings with sequences $\left\{h_{n}\right\},\left\{k_{n}\right\} \in[1, \infty)$ and $T_{1}, T_{2}: K \rightarrow E$ are two total asymptotically nonexpansive non-self mappings with sequences $\left\{\mu_{n}\right\},\left\{\mu_{n_{1}}\right\} \in[0, \infty)$ and $\left\{\nu_{n}\right\},\left\{\nu_{n_{1}}\right\} \in[0, \infty)$. Let $\left\{x_{n}\right\}$ be the sequence defined by (7), where $\left\{\alpha_{n}\right\}$ and $\left\{\beta_{n}\right\}$ are real sequences in $[0,1)$. Suppose that $F=F\left(S_{1}\right) \bigcap F\left(S_{2}\right) \bigcap F\left(T_{1}\right) \bigcap F\left(T_{2}\right) \neq \emptyset$. If the following conditions hold:

(i) $\sum_{n=1}^{\infty}\left(h_{n} k_{n}-1\right)<\infty$;

(ii) $\sum_{n=1}^{\infty} \mu_{n}<\infty, \sum_{n=1}^{\infty} \mu_{n_{1}}<\infty, \sum_{n=1}^{\infty} \nu_{n}<\infty, \sum_{n=1}^{\infty} \nu_{n_{1}}<\infty$;

(iii) there exists a constant $M>0$ such that $\psi(t) \leq M t, t \geq 0$.

Then $\lim _{n \rightarrow \infty}\left\|x_{n}-q\right\|$ and $\lim _{n \rightarrow \infty} d\left(x_{n}, F\right)$ both exist for all $q \in F$.

Proof. Let $q \in F$ and let $\rho_{n}=\max \left\{\mu_{n}, \mu_{n_{1}}\right\}, \theta_{n}=\max \left\{\nu_{n}, \nu_{n_{1}}\right\}$ with $\sum_{n=1}^{\infty} \rho_{n}<\infty$ and $\sum_{n=1}^{\infty} \theta_{n}<\infty$. From (7), we have

$$
\begin{aligned}
\left\|y_{n}-q\right\| & =\left\|P\left(\left(1-\beta_{n}\right) S_{2}^{n} x_{n}+\beta_{n} T_{2}\left(P T_{2}\right)^{n-1} x_{n}\right)-P(q)\right\| \\
& \leq\left\|\left(1-\beta_{n}\right) S_{2}^{n} x_{n}+\beta_{n} T_{2}\left(P T_{2}\right)^{n-1} x_{n}-q\right\| \\
& =\left\|\left(1-\beta_{n}\right)\left(S_{2}^{n} x_{n}-q\right)+\beta_{n}\left(T_{2}\left(P T_{2}\right)^{n-1} x_{n}-q\right)\right\| \\
& \leq\left(1-\beta_{n}\right)\left\|S_{2}^{n} x_{n}-q\right\|+\beta_{n}\left\|T_{2}\left(P T_{2}\right)^{n-1} x_{n}-q\right\| \\
& \leq\left(1-\beta_{n}\right) k_{n}\left\|x_{n}-q\right\|+\beta_{n}\left[\left\|x_{n}-q\right\|+\mu_{n_{1}} \psi\left(\left\|x_{n}-q\right\|\right)+\nu_{n_{1}}\right] \\
& \leq\left(1-\beta_{n}\right) k_{n}\left\|x_{n}-q\right\|+\beta_{n}\left[\left\|x_{n}-q\right\|+\rho_{n} M\left\|x_{n}-q\right\|+\theta_{n}\right] \\
& \leq\left(1-\beta_{n}\right) k_{n}\left\|x_{n}-q\right\|+\beta_{n} k_{n}\left\|x_{n}-q\right\|+\rho_{n} M\left\|x_{n}-q\right\|+\theta_{n} \\
(8) & =\left(k_{n}+\rho_{n} M\right)\left\|x_{n}-q\right\|+\theta_{n} .
\end{aligned}
$$

Again using (7), we have

$$
\begin{aligned}
&\left\|x_{n+1}-q\right\|=\left\|P\left(\left(1-\alpha_{n}\right) S_{1}^{n} x_{n}+\alpha_{n} T_{1}\left(P T_{1}\right)^{n-1} y_{n}\right)-P(q)\right\| \\
& \leq\left\|\left(1-\alpha_{n}\right) S_{1}^{n} x_{n}+\alpha_{n} T_{1}\left(P T_{1}\right)^{n-1} y_{n}-q\right\| \\
&=\left\|\left(1-\alpha_{n}\right)\left(S_{1}^{n} x_{n}-q\right)+\alpha_{n}\left(T_{1}\left(P T_{1}\right)^{n-1} y_{n}-q\right)\right\| \\
& \leq\left(1-\alpha_{n}\right)\left\|S_{1}^{n} x_{n}-q\right\|+\alpha_{n}\left\|T_{1}\left(P T_{1}\right)^{n-1} y_{n}-q\right\| \\
& \leq\left(1-\alpha_{n}\right) h_{n}\left\|x_{n}-q\right\|+\alpha_{n}\left[\left\|y_{n}-q\right\|+\mu_{n} \psi\left(\left\|y_{n}-q\right\|\right)+\nu_{n}\right] \\
& \leq\left(1-\alpha_{n}\right) h_{n}\left\|x_{n}-q\right\|+\alpha_{n}\left[\left\|y_{n}-q\right\|+\rho_{n} M\left\|y_{n}-q\right\|+\theta_{n}\right] \\
&(9) \leq\left(1-\alpha_{n}\right) h_{n}\left\|x_{n}-q\right\|+\alpha_{n}\left(1+\rho_{n} M\right)\left\|y_{n}-q\right\|+\theta_{n} .
\end{aligned}
$$

Using equation (8) in (9), we obtain

$$
\begin{aligned}
\left\|x_{n+1}-q\right\| \leq & \left(1-\alpha_{n}\right) h_{n}\left\|x_{n}-q\right\|+\alpha_{n}\left(1+\rho_{n} M\right) \times \\
& {\left[\left(k_{n}+\rho_{n} M\right)\left\|x_{n}-q\right\|+\theta_{n}\right]+\theta_{n} } \\
\leq & \left(1-\alpha_{n}\right) h_{n}\left\|x_{n}-q\right\|+\alpha_{n}\left(1+\rho_{n} M\right) \times \\
& \left(k_{n}+\rho_{n} M\right)\left\|x_{n}-q\right\|+\left(1+\rho_{n} M\right) \theta_{n}+\theta_{n} \\
= & {\left[\left(1-\alpha_{n}\right) h_{n}+\alpha_{n}\left(1+\rho_{n} M\right)\left(k_{n}+\rho_{n} M\right)\right]\left\|x_{n}-q\right\| } \\
& +\left(2+\rho_{n} M\right) \theta_{n}
\end{aligned}
$$


(10)

$$
\begin{aligned}
\leq & {\left[\left(1-\alpha_{n}\right) h_{n} k_{n}+\alpha_{n} h_{n} k_{n}+\rho_{n} M\left(1+k_{n}+\rho_{n} M\right)\right]\left\|x_{n}-q\right\| } \\
& +\left(2+\rho_{n} M\right) \theta_{n} \\
= & {\left[1+\left(h_{n} k_{n}-1\right)+\rho_{n} M\left(1+k_{n}+\rho_{n} M\right)\right]\left\|x_{n}-q\right\| } \\
& +\left(2+\rho_{n} M\right) \theta_{n} \\
\leq & \left(1+t_{n}\right)\left\|x_{n}-q\right\|+R \theta_{n}
\end{aligned}
$$

where $t_{n}=\left(h_{n} k_{n}-1\right)+\rho_{n} M\left(1+k_{n}+\rho_{n} M\right)$ and for some $R>0$. Since $\sum_{n=1}^{\infty}\left(h_{n} k_{n}-1\right)<\infty$ and $\sum_{n=1}^{\infty} \rho_{n}<\infty$, it follows that $\sum_{n=1}^{\infty} t_{n}<\infty$. Now, since $\sum_{n=1}^{\infty} t_{n}<\infty$ and $\sum_{n=1}^{\infty} \theta_{n}<\infty$, it follows from Lemma 1.1 that $\lim _{n \rightarrow \infty}\left\|x_{n}-q\right\|$ exists.

Now, taking the infimum over all $q \in F$ in (10), we have

$$
d\left(x_{n+1}, F\right) \leq\left[1+t_{n}\right] d\left(x_{n}, F\right)+R \theta_{n}
$$

for all $n \in \mathbf{N}$. it follows from $\sum_{n=1}^{\infty} t_{n}<\infty, \sum_{n=1}^{\infty} \theta_{n}<\infty$ and Lemma 1.1 that $\lim _{n \rightarrow \infty} d\left(x_{n}, F\right)$ exists. This completes the proof.

Theorem 2.1. Let $E$ be a real Banach space, $K$ be a nonempty closed convex subset of $E$. Let $S_{1}, S_{2}: K \rightarrow K$ be two asymptotically nonexpansive self mappings with sequences $\left\{h_{n}\right\},\left\{k_{n}\right\} \in[1, \infty)$ and $T_{1}, T_{2}: K \rightarrow E$ are two total asymptotically nonexpansive non-self mappings with sequences $\left\{\mu_{n}\right\},\left\{\mu_{n_{1}}\right\} \in[0, \infty)$ and $\left\{\nu_{n}\right\},\left\{\nu_{n_{1}}\right\} \in[0, \infty)$. Let $\left\{x_{n}\right\}$ be the sequence defined by (7), where $\left\{\alpha_{n}\right\}$ and $\left\{\beta_{n}\right\}$ are real sequences in $[0,1)$. Suppose that $F=F\left(S_{1}\right) \bigcap F\left(S_{2}\right) \bigcap F\left(T_{1}\right) \bigcap F\left(T_{2}\right) \neq \emptyset$ is closed. If the following conditions hold:

(i) $\sum_{n=1}^{\infty}\left(h_{n} k_{n}-1\right)<\infty$;

(ii) $\sum_{n=1}^{\infty} \mu_{n}<\infty, \sum_{n=1}^{\infty} \mu_{n_{1}}<\infty, \sum_{n=1}^{\infty} \nu_{n}<\infty, \sum_{n=1}^{\infty} \nu_{n_{1}}<\infty$;

(iii) there exists a constant $M>0$ such that $\psi(t) \leq M t, t \geq 0$.

Then $\left\{x_{n}\right\}$ converges strongly to a common fixed point of $S_{1}, S_{2}, T_{1}$ and $T_{2}$ if and only if $\liminf _{n \rightarrow \infty} d\left(x_{n}, F\right)=0$, where $d(x, F)=\inf \{\|x-p\|: p \in F\}$.

Proof. The necessity is obvious. Indeed, if $x_{n} \rightarrow q \in F$ as $n \rightarrow \infty$, then

$$
d\left(x_{n}, F\right)=\inf _{q \in F} d\left(x_{n}, q\right) \leq\left\|x_{n}-q\right\| \rightarrow 0(n \rightarrow \infty) .
$$

Thus $\liminf \operatorname{in}_{n \rightarrow \infty} d\left(x_{n}, F\right)=0$.

Conversely, suppose that $\liminf _{n \rightarrow \infty} d\left(x_{n}, F\right)=0$. By Lemma 2.1, we have that $\lim _{n \rightarrow \infty} d\left(x_{n}, F\right)$ exists. Further, by assumption $\liminf _{n \rightarrow \infty} d\left(x_{n}, F\right)$ $=0$, from (11) and Lemma 1.1(ii), we conclude that $\lim _{n \rightarrow \infty} d\left(x_{n}, F\right)=0$. Now, we show that $\left\{x_{n}\right\}$ is a Cauchy sequence in $E$. Indeed, from (10), we have

$$
\left\|x_{n+1}-q\right\| \leq\left[1+t_{n}\right]\left\|x_{n}-q\right\|+R \theta_{n}
$$

for each $n \in \mathbf{N}$, with $\sum_{n=1}^{\infty} t_{n}<\infty, \sum_{n=1}^{\infty} \theta_{n}<\infty$ and $q \in F$. For any $m, n, m>n \in \mathbf{N}$, we have

$$
\left\|x_{m}-q\right\| \leq\left[1+t_{m-1}\right]\left\|x_{m-1}-q\right\|+R \theta_{m-1}
$$




$$
\begin{aligned}
& \leq e^{t_{m-1}}\left\|x_{m-1}-q\right\|+R \theta_{m-1} \\
& \vdots \\
& \leq\left(e^{\sum_{i=n}^{m-1} t_{i}}\right)\left\|x_{n}-q\right\|+R\left(e^{\sum_{i=n+1}^{m-1} t_{i}}\right) \sum_{i=n}^{m-1} \theta_{i} \\
& \leq R^{\prime}\left\|x_{n}-q\right\|+R R^{\prime} \sum_{i=n}^{m-1} \theta_{i}
\end{aligned}
$$

where $R^{\prime}=e^{\sum_{i=n}^{\infty} t_{i}}$.

Thus for any $q \in F$, we have

$$
\begin{aligned}
\left\|x_{n}-x_{m}\right\| & \leq\left\|x_{n}-q\right\|+\left\|x_{m}-q\right\| \\
& \leq\left\|x_{n}-q\right\|+R^{\prime}\left\|x_{n}-q\right\|+R R^{\prime} \sum_{i=n}^{m-1} \theta_{i} \\
& \leq\left(R^{\prime}+1\right)\left\|x_{n}-q\right\|+R R^{\prime} \sum_{i=n}^{\infty} \theta_{i}
\end{aligned}
$$

Taking the infimum over all $q \in F$, we obtain

$$
\left\|x_{n}-x_{m}\right\| \leq\left(R^{\prime}+1\right) d\left(x_{n}, F\right)+R R^{\prime} \sum_{i=n}^{\infty} \theta_{i} .
$$

Thus it follows from $\lim _{n \rightarrow \infty} d\left(x_{n}, F\right)=0$ and $\theta_{n} \rightarrow 0$ as $n \rightarrow \infty$ that $\left\{x_{n}\right\}$ is a Cauchy sequence in $K$. Since $K$ is closed subset of $E$, the sequence $\left\{x_{n}\right\}$ converges strongly to some $p^{*} \in K$. Next, we show that $p^{*} \in F$. Now, $\lim _{n \rightarrow \infty} d\left(x_{n}, F\right)=0$ gives that $d\left(p^{*}, F\right)=0$. Since $F$ is closed, $p^{*} \in F$. Thus $p^{*}$ is a common fixed point of $S_{1}, S_{2}, T_{1}$ and $T_{2}$. This completes the proof.

Theorem 2.2. Let $E$ be a real Banach space, $K$ be a nonempty closed convex subset of $E$. Let $S_{1}, S_{2}: K \rightarrow K$ be two asymptotically nonexpansive self mappings with sequences $\left\{h_{n}\right\},\left\{k_{n}\right\} \in[1, \infty)$ and $T_{1}, T_{2}: K \rightarrow E$ are two total asymptotically nonexpansive non-self mappings with sequences $\left\{\mu_{n}\right\},\left\{\mu_{n_{1}}\right\} \in[0, \infty)$ and $\left\{\nu_{n}\right\},\left\{\nu_{n_{1}}\right\} \in[0, \infty)$. Let $\left\{x_{n}\right\}$ be the sequence defined by (7), where $\left\{\alpha_{n}\right\}$ and $\left\{\beta_{n}\right\}$ are real sequences in $[0,1)$. Suppose that $F=F\left(S_{1}\right) \bigcap F\left(S_{2}\right) \bigcap F\left(T_{1}\right) \bigcap F\left(T_{2}\right) \neq \emptyset$. Assume that one of $S_{1}, S_{2}, T_{1}$ and $T_{2}$ is completely continuous and $\lim _{n \rightarrow \infty}\left\|x_{n}-S_{i} x_{n}\right\|=$ $\lim _{n \rightarrow \infty}\left\|x_{n}-T_{i} x_{n}\right\|=0$ for $i=1,2$. If the following conditions hold:

(i) $\sum_{n=1}^{\infty}\left(h_{n} k_{n}-1\right)<\infty$;

(ii) $\sum_{n=1}^{\infty} \mu_{n}<\infty, \sum_{n=1}^{\infty} \mu_{n_{1}}<\infty, \sum_{n=1}^{\infty} \nu_{n}<\infty, \sum_{n=1}^{\infty} \nu_{n_{1}}<\infty$;

(iii) there exists a constant $M>0$ such that $\psi(t) \leq M t, t \geq 0$. 
Then $\left\{x_{n}\right\}$ converges strongly to a common fixed point of $S_{1}, S_{2}, T_{1}$ and $T_{2}$.

Proof. Without loss of generality we can assume that $S_{1}$ is completely continuous. Since $\left\{x_{n}\right\}$ is bounded by Lemma 2.1, there exists a subsequence $\left\{S_{1} x_{n_{k}}\right\}$ of $\left\{S_{1} x_{n}\right\}$ such that $\left\{S_{1} x_{n_{k}}\right\}$ converges strongly to some $q^{*} \in K$. Moreover, by hypothesis of the theorem we know that

$$
\lim _{k \rightarrow \infty}\left\|x_{n_{k}}-S_{1} x_{n_{k}}\right\|=\lim _{k \rightarrow \infty}\left\|x_{n_{k}}-S_{2} x_{n_{k}}\right\|=0
$$

and

which implies that

$$
\lim _{k \rightarrow \infty}\left\|x_{n_{k}}-T_{1} x_{n_{k}}\right\|=\lim _{k \rightarrow \infty}\left\|x_{n_{k}}-T_{2} x_{n_{k}}\right\|=0
$$

$$
\left\|x_{n_{k}}-q^{*}\right\| \leq\left\|x_{n_{k}}-S_{1} x_{n_{k}}\right\|+\left\|S_{1} x_{n_{k}}-q^{*}\right\| \rightarrow 0
$$

as $k \rightarrow \infty$ and so $x_{n_{k}} \rightarrow q^{*} \in K$. Thus, by the continuity of $S_{1}, S_{2}, T_{1}$ and $T_{2}$, we have

$$
\left\|q^{*}-S_{i} q^{*}\right\|=\lim _{k \rightarrow \infty}\left\|x_{n_{k}}-S_{i} x_{n_{k}}\right\|=0
$$

and

$$
\left\|q^{*}-T_{i} q^{*}\right\|=\lim _{k \rightarrow \infty}\left\|x_{n_{k}}-T_{i} x_{n_{k}}\right\|=0
$$

for $i=1,2$. Thus it follows that $q^{*} \in F=F\left(S_{1}\right) \bigcap F\left(S_{2}\right) \bigcap F\left(T_{1}\right) \bigcap F\left(T_{2}\right)$. Again, since $\lim _{n \rightarrow \infty}\left\|x_{n}-q^{*}\right\|$ exists by Lemma 2.1, we have $\lim _{n \rightarrow \infty} \| x_{n}-$ $q^{*} \|=0$. This shows that the sequence $\left\{x_{n}\right\}$ converges strongly to a common fixed point of $S_{1}, S_{2}, T_{1}$ and $T_{2}$. This completes the proof.

Theorem 2.3. Let $E$ be a real Banach space, $K$ be a nonempty closed convex subset of $E$. Let $S_{1}, S_{2}: K \rightarrow K$ be two asymptotically nonexpansive self mappings with sequences $\left\{h_{n}\right\},\left\{k_{n}\right\} \in[1, \infty)$ and $T_{1}, T_{2}: K \rightarrow E$ are two total asymptotically nonexpansive non-self mappings with sequences $\left\{\mu_{n}\right\},\left\{\mu_{n_{1}}\right\} \in[0, \infty)$ and $\left\{\nu_{n}\right\},\left\{\nu_{n_{1}}\right\} \in[0, \infty)$. Let $\left\{x_{n}\right\}$ be the sequence defined by (7), where $\left\{\alpha_{n}\right\}$ and $\left\{\beta_{n}\right\}$ are real sequences in $[0,1)$. Suppose that $F=F\left(S_{1}\right) \bigcap F\left(S_{2}\right) \bigcap F\left(T_{1}\right) \bigcap F\left(T_{2}\right) \neq \emptyset$. Assume that one of $S_{1}, S_{2}, T_{1}$ and $T_{2}$ is semi-compact and $\lim _{n \rightarrow \infty}\left\|x_{n}-S_{i} x_{n}\right\|=\lim _{n \rightarrow \infty}\left\|x_{n}-T_{i} x_{n}\right\|=0$ for $i=1,2$. If the following conditions hold:

(i) $\sum_{n=1}^{\infty}\left(h_{n} k_{n}-1\right)<\infty$;

(ii) $\sum_{n=1}^{\infty} \mu_{n}<\infty, \sum_{n=1}^{\infty} \mu_{n_{1}}<\infty, \sum_{n=1}^{\infty} \nu_{n}<\infty, \sum_{n=1}^{\infty} \nu_{n_{1}}<\infty$;

(iii) there exists a constant $M>0$ such that $\psi(t) \leq M t, t \geq 0$.

Then $\left\{x_{n}\right\}$ converges strongly to a common fixed point of $S_{1}, S_{2}, T_{1}$ and $T_{2}$.

Proof. Since by hypothesis $\lim _{n \rightarrow \infty}\left\|x_{n}-S_{i} x_{n}\right\|=\lim _{n \rightarrow \infty}\left\|x_{n}-T_{i} x_{n}\right\|=0$ for $i=1,2$ and one of $S_{1}, S_{2}, T_{1}$ and $T_{2}$ is semi-compact, there exists a subsequence $\left\{x_{n_{j}}\right\}$ of $\left\{x_{n}\right\}$ such that $\left\{x_{n_{j}}\right\}$ converges strongly to some $p^{*} \in$ $K$. Moreover, by the continuity of $S_{1}, S_{2}, T_{1}$ and $T_{2}$, we have $\left\|p^{*}-S_{i} p^{*}\right\|=$ $\lim _{j \rightarrow \infty}\left\|x_{n_{j}}-S_{i} x_{n_{j}}\right\|=0$ and $\left\|p^{*}-T_{i} p^{*}\right\|=\lim _{j \rightarrow \infty}\left\|x_{n_{j}}-T_{i} x_{n_{j}}\right\|=0$ 
for $i=1,2$. Thus it follows that $p^{*} \in F=F\left(S_{1}\right) \bigcap F\left(S_{2}\right) \bigcap F\left(T_{1}\right) \bigcap F\left(T_{2}\right)$. Since $\lim _{n \rightarrow \infty}\left\|x_{n}-p^{*}\right\|$ exists by Lemma 2.1, we have $\lim _{n \rightarrow \infty}\left\|x_{n}-p^{*}\right\|=0$. This shows that the sequence $\left\{x_{n}\right\}$ converges strongly to a common fixed point of $S_{1}, S_{2}, T_{1}$ and $T_{2}$. This completes the proof.

Theorem 2.4. Let $E$ be a real Banach space, $K$ be a nonempty closed convex subset of $E$. Let $S_{1}, S_{2}: K \rightarrow K$ be two asymptotically nonexpansive self mappings with sequences $\left\{h_{n}\right\},\left\{k_{n}\right\} \in[1, \infty)$ and $T_{1}, T_{2}: K \rightarrow E$ are two total asymptotically nonexpansive non-self mappings with sequences $\left\{\mu_{n}\right\},\left\{\mu_{n_{1}}\right\} \in[0, \infty)$ and $\left\{\nu_{n}\right\},\left\{\nu_{n_{1}}\right\} \in[0, \infty)$. Let $\left\{x_{n}\right\}$ be the sequence defined by (7), where $\left\{\alpha_{n}\right\}$ and $\left\{\beta_{n}\right\}$ are real sequences in $[0,1)$. Suppose that $F=F\left(S_{1}\right) \bigcap F\left(S_{2}\right) \bigcap F\left(T_{1}\right) \bigcap F\left(T_{2}\right) \neq \emptyset$ and the following conditions hold:

(i) $\sum_{n=1}^{\infty}\left(h_{n} k_{n}-1\right)<\infty$;

(ii) $\sum_{n=1}^{\infty} \mu_{n}<\infty, \sum_{n=1}^{\infty} \mu_{n_{1}}<\infty, \sum_{n=1}^{\infty} \nu_{n}<\infty, \sum_{n=1}^{\infty} \nu_{n_{1}}<\infty$;

(iii) there exists a constant $M>0$ such that $\psi(t) \leq M t, t \geq 0$.

If $S_{1}, S_{2}, T_{1}$ and $T_{2}$ satisfy the following conditions:

$\left(C_{1}\right) \lim _{n \rightarrow \infty}\left\|x_{n}-S_{i} x_{n}\right\|=\lim _{n \rightarrow \infty}\left\|x_{n}-T_{i} x_{n}\right\|=0$ for $i=1,2$;

$\left(C_{2}\right)$ there exists a continuous function $f:[0, \infty) \rightarrow[0, \infty)$ with $\left.f 0\right)=0$ and $f(t)>0$ for all $t \in(0, \infty)$ such that

$$
f(d(x, F)) \leq a_{1}\left\|x-S_{1} x\right\|+a_{2}\left\|x-S_{2} x\right\|+a_{3}\left\|x-T_{1} x\right\|+a_{4}\left\|x-T_{2} x\right\|
$$

for all $x \in K$, and $a_{1}, a_{2}, a_{3}, a_{4}$ are nonnegative real numbers such that $a_{1}+a_{2}+a_{3}+a_{4}=1$, where $d(x, F)=\inf \{\|x-p\|: p \in F\}$.

Then the sequence $\left\{x_{n}\right\}$ converges strongly to a common fixed point of $S_{1}$, $S_{2}, T_{1}$ and $T_{2}$.

Proof. It follows from the hypothesis that

$$
\begin{aligned}
\lim _{n \rightarrow \infty} f\left(d\left(x_{n}, F\right)\right) \leq & a_{1} \cdot\left\|x_{n}-S_{1} x_{n}\right\|+a_{2} \cdot\left\|x_{n}-S_{2} x_{n}\right\| \\
& +a_{3} \cdot\left\|x_{n}-T_{1} x_{n}\right\|+a_{4} \cdot\left\|x_{n}-T_{2} x_{n}\right\| \\
= & 0 .
\end{aligned}
$$

That is,

$$
\lim _{n \rightarrow \infty} f\left(d\left(x_{n}, F\right)\right)=0 .
$$

Since $f:[0, \infty) \rightarrow[0, \infty)$ is a continuous function and $f(0)=0$, therefore we have

$$
\lim _{n \rightarrow \infty} d\left(x_{n}, F\right)=0 .
$$

Therefore, Theorem 2.1 implies that $\left\{x_{n}\right\}$ must converges strongly to a common fixed point of $S_{1}, S_{2}, T_{1}$ and $T_{2}$. This completes the proof.

Example 2.1. Let $E=\mathbb{R}$ be the real line with the usual norm $\|\|=.|$.$| ,$ $K=[-1,1]$ and $P$ be the identity mapping. For each $x \in K$, define two 
mappings $T, S: K \rightarrow K$ by

$$
T(x)=\left\{\begin{array}{cl}
-2 \sin \frac{x}{2}, & \text { if } x \in[0,1], \\
2 \sin \frac{x}{2}, & \text { if } x \in[-1,0) .
\end{array}\right.
$$

and

$$
S(x)= \begin{cases}\frac{x}{2}, & \text { if } x \neq 0 \\ 0, & \text { if } x=0 .\end{cases}
$$

Then $T$ is an asymptotically nonexpansive mapping with constant sequence $\left\{k_{n}\right\}=\{1\}$ for all $n \geq 1$ and uniformly $L$-Lipschtzian mapping with $L=\sup _{n \geq 1}\left\{k_{n}\right\}$ and hence it is a total asymptotically nonexpansive mapping by remark 1.1 and $S$ is an asymptotically nonexpansive mapping with constant sequence $\left\{k_{n}\right\}=\{1\}$ for all $n \geq 1$. Also $F(T)=\{0\}$ is the unique fixed point of $T$ and $F(S)=\{0\}$ is the unique fixed point of $S$, that is, $F=F(S) \cap F(T)=\{0\}$ is the unique hybrid common fixed point of $S$ and $T$.

\section{Concluding Remarks}

In this paper, we study hybrid mixed type iteration scheme for two asymptotically nonexpansive self mappings and two total asymptotically nonexpansive non-self mappings and establish some strong convergence theorems using completely continuous and semi-compactness conditions in the framework of real Banach spaces. Our results extend and generalize the corresponding results of $[2,3,6,7,8,9,10,11,12,13]$.

\section{REFERENCES}

[1] Ya. I. Albert, C. E. Chidume, H. Zegeye, Approximating fixed point of total asymptotically nonexpansive mappings, Fixed Point Theory Appl. (2006) Art. ID 10673.

[2] C. E. Chidume, E. U. Ofoedu, H. Zegeye, Strong and weak convergence theorems for asymptotically nonexpansive mappings, J. Math. Anal. Appl., 280 (2003), 364-374.

[3] C. E. Chidume, N. Shahzad, H. Zegeye, Convergence theorems for mappings which are asymptotically nonexpansive in the intermediate sense, Numerical Functional and Optimization, textbf25, No. 3-4 (2004), 239-257.

[4] C. E. Chidume, E. U. Ofoedu, Approximation of common fixed points for finite families of total asymptotically nonexpansive mappings, J. Math. Anal. Appl., 333 (2007), $128-141$.

[5] K. Goebel, W. A. Kirk, A fixed point theorem for asymptotically nonexpansive mappings, Proc. Amer. Math. Soc., 35, No. 1 (1972), 171-174.

[6] W. P. Guo, Y. J. Cho, W. Guo, Convergence theorems for mixed type asymptotically nonexpansive mappings, Fixed Point Theory Appl., (2012), 2012:224.

[7] S. H. Khan, W. Takahashi, Approximating common fixed points of two asymptotically nonexpansive mappings, Sci. Math. Jpn., 53, No. 1 (2001), 143-148. 
[8] M. O. Osilike, S. C. Aniagbosor, Weak and strong convergence theorems for fixed points of asymptotically nonexpansive mappings, Math. Comput. Modelling, 32 (2000), 1181-1191.

[9] B. E. Rhoades, Fixed point iteration for certain nonlinear mappings, J. Math. Anal. Appl., 183 (1994), 118-120.

[10] J. Schu, Weak and strong convergence to fixed points of asymptotically nonexpansive mappings, Bull. Austral. Math. Soc., 43, No. 1 (1991), 153-159.

[11] K. K. Tan, H. K. Xu, Approximating fixed points of nonexpansive mappings by the Ishikawa iteration process, J. Math. Anal. Appl., 178 (1993), 301-308.

[12] L. Wang, Strong and weak convergence theorems for common fixed point of nonself asymptotically nonexpansive mappings, J. Mth. Anal. Appl., 323, No. 1 (2006), 550557.

[13] S. Wei, W. P. Guo, Strong convergence theorems for mixed type asymptotically nonexpansive mappings, Comm. Math. Res., 31 (2015), 149-160.

[14] E. Yolacan, H. Kiziltunc, On convergence theorems for total asymptotically nonexpansive non-self mappings in Banach spaces, J. Nonlinear Sci. Appl., 5 (2012), 389-402.

\author{
G.S. SAluJa \\ Department of Mathematics \\ Govt. N.P.G. College of Science \\ RAIPUR - 492010 (C.G.) \\ INDIA \\ E-mail address: saluja1963@gmail.com
}

